\title{
The Negative Inotropic Effect of $\beta_{3}$-Adrenoceptor Stimulation Is Mediated by Activation of a Nitric Oxide Synthase Pathway in Human Ventricle
}

\author{
Chantal Gauthier, ${ }^{\star \ddagger}$ Véronique Leblais, ${ }^{*}$ Lester Kobzik, ${ }^{\S}$ Jean-Noël Trochu, ${ }^{\star}$ Nassirah Khandoudi, ${ }^{\|}$Antoine Bril, \\ Jean-Luc Balligand," and Hervé Le Marec* \\ *Laboratoire de Physiopathologie et Pharmacologie Cellulaires et Moléculaires, INSERM CJF 96-01, CHU de Nantes, 44322 Nantes, \\ France; ${ }^{\ddagger}$ Faculté des Sciences et Techniques, Université de Nantes, 44093 Nantes, France; ${ }^{\S}$ Department of Pathology, Brigham and \\ Women's Hospital, and Physiology Program, Harvard School of Public Health, Boston, Massachusetts 02115; "SmithKline Beecham, \\ Laboratoires Pharmaceutiques, 35762 Saint Grégoire, France; and "Department of Medicine, Pharmacology Unit, University of Louvain \\ Medical School, Brussels B1200, Belgium
}

\begin{abstract}
$\beta_{1}$ - and $\beta_{2}$-adrenoceptors in heart muscle cells mediate the catecholamine-induced increase in the force and frequency of cardiac contraction. Recently, in addition, we demonstrated the functional expression of $\beta_{3}$-adrenoceptors in the human heart. Their stimulation, in marked contrast with that of $\beta_{1}$-and $\beta_{2}$-adrenoceptors, induces a decrease in contractility through presently unknown mechanisms. In the present study, we examined the role of a nitric oxide (NO) synthase pathway in mediating the $\beta_{3}$-adrenoceptor effect on the contractility of human endomyocardial biopsies. The negative inotropic effects of a $\beta_{3}$-adrenoceptor agonist, BRL 37344 , and also of norepinephrine in the presence of $\alpha$ - and $\beta_{1-2}$-blockade were inhibited both by a nonspecific blocker of NO, methylene blue, and two NO synthase (NOS) inhibitors, L- $N$-monomethyl-arginine and L-nitroarginine-methyl ester. The effect of the NOS inhibitors was reversed by an excess of L-arginine, the natural substrate of NOS, but not by $D$-arginine. Moreover, the effects of the $\beta_{3}$-adrenoceptor agonist on contractility were associated with parallel increases in the production of NO and intracellular cGMP, which were also inhibited by NOS inhibitors. Immunohistochemical staining of human ventricular biopsies showed the expression of the endothelial constitutive (eNOS), but not the inducible (iNOS) isoform of NOS in both ventricular myocytes and endothelial cells. These results demonstrate that $\beta_{3}$-adrenoceptor stimulation decreases cardiac contractility through activation of an NOS pathway. Changes in the expression of this pathway may alter the balance between positive and negative inotropic effects of catecholamines on the heart potentially leading to myocardial dys-
\end{abstract}

Address correspondence to Chantal Gauthier, Laboratoire de Physiopathologie et Pharmacologie Cellulaires et Moléculaires, INSERM CJF 96-01, Aile Nord $4{ }^{\text {ème }}$ étage, 1 place Alexis Ricordeau, 44093 Nantes Cedex, France. Phone: 33-2-40-08-75-19; FAX: 33-2-40-08-7523; E-mail: chantal.gauthier@sante.univ-nantes.fr or Jean-Luc Balligand, Department of Medicine, Pharmacology Unit, University of Louvain Medical School, FATH 53.49, Tour Pasteur +2, 53, Avenue E. Mounier, 1200 Brussels, Belgium. Phone: 32-2-764-5349; FAX: 322-764-9322; E-mail: balligand@mint.ucl.ac.be

Received for publication 7 November 1997 and accepted in revised form 5 August 1998.

J. Clin. Invest.

(c) The American Society for Clinical Investigation, Inc. 0021-9738/98/10/1377/08 \$2.00

Volume 102, Number 7, October 1998, 1377-1384

http://www.jci.org function. (J. Clin. Invest. 1998. 102:1377-1384.) Key words: $\beta$-adrenoceptors • human myocardium • nitric oxide • cGMP • contractility

\section{Introduction}

Recently, we provided evidence for the functional expression of a third $\beta$-adrenoceptor subtype, $\beta_{3}$, in human ventricle (1), suggesting that at least three $\beta$-adrenoceptor populations can modulate human cardiac function. In the human heart, both $\beta_{1}$ - and $\beta_{2}$-adrenoceptors mediate an increase in heart rate, contraction force, and acceleration of relaxation (2). To a large extent, these effects result from an elevation of intracellular cAMP after adenylyl cyclase stimulation through $\mathrm{G}_{\mathrm{s}}$ proteins (3). In contrast with $\beta_{1^{-}}$and $\beta_{2}$-adrenoceptors, stimulation of the $\beta_{3}$-adrenoceptor in human ventricular muscle reduces contractile force through an as yet undetermined mechanism (1).

Several intracellular pathways may mediate a decrease in cardiac contractility. Among them, increasing evidence indicates that nitric oxide $(\mathrm{NO})^{1}$ endogenously produced within heart cells plays a functional role in decreasing cardiac contraction in response to activation of the autonomic nervous system (for reviews see references 4 and 5). NO is produced by two constitutively expressed, calcium-sensitive isoforms and one inducible, calcium-insensitive isoform of NO synthase (NOS) that catalyze the oxygen- and NADPH-dependent oxidation of the cationic acid, L-arginine, leading to the production of L-citrulline. Specific mRNAs and proteins have been identified for both endothelial constitutive NOS (eNOS) and inducible NOS (iNOS) in ventricular myocytes from different species, including humans $(6,7)$. Experiments with various models have shown that activation of the NO pathway attenuates the effect of submaximal concentrations of catecholamines in the heart (7-10). Of interest, this has also been confirmed in patients with left ventricular dysfunction (11). Conversely, the NO-dependent parasympathetic attenuation of adrenergically stimulated calcium current is completely abolished in transgenic mice in which the eNOS gene has been disrupted (eNOS -/-; 12). Altogether, these studies emphasize the role of NO as a second messenger opposing the classical positive inotropic (and chronotropic) action of catecholamines in the heart, at least at concentrations likely to be generated endogenously within ventricular muscle.

1. Abbreviations used in this paper: eNOS, endothelial constitutive NOS; iNOS, inducible NOS; L-NAME, $N^{\mathrm{G}}$-nitro-L-arginine methyl ester; L-NMMA, $N^{\mathrm{G}}$-monomethyl-L-arginine, monoacetate; NO, nitric oxide; NOS, NO synthase. 
Since $\beta_{3}$-adrenoceptor stimulation induces effects (mainly decreased contractility) similar to those of NO in cardiac muscle, this study investigated the role of the NO pathway in mediating the effect of $\beta_{3}$-adrenoceptor stimulation in human ventricular muscle. Concurrent analyses of the effects of NOS inhibition on contractile parameters, intracellular cGMP levels, and NO production showed that the negative inotropic effect of $\beta_{3}$-adrenergic agonists is mediated by activation of NO synthesis, probably through eNOS identified by immunohistochemistry in human endomyocardial biopsies.

\section{Methods}

Human ventricular biopsies. All protocols were approved by the Ethics Committee of the Centre National de la Recherche Scientifique (France). 54 human endomyocardial biopsies were obtained from the right interventricular septum of cardiac transplant patients (43 men and 11 women; mean age $51.3 \pm 1.6 \mathrm{yr}$ ) during right jugular vein catheterization performed routinely to detect possible rejection. None of the patients showed evidence of cardiac rejection. All received immunosuppressive therapy (azathioprine, prednisolone, and cyclosporine). In addition, 16 were given a calcium antagonist, 4 a $\beta$-adrenoceptor antagonist, 6 an $\alpha$-adrenoceptor antagonist, and 12 a diuretic. 23 had not undergone treatment known to produce cardiovascular effects. The effects of $\beta_{3}$-adrenoceptor agonists obtained in biopsies from patients under these different treatments were similar to those obtained in biopsies from patients not receiving these drugs.

Drugs. Methylene blue, D-arginine, $N^{\mathrm{G}}$-nitro-L-arginine methyl ester (L-NAME), norepinephrine, prazosine, nadolol, and pertussis toxin were obtained from Sigma Chemical Co. (St. Louis, MO). $N^{\mathrm{G}}$ monomethyl-L-arginine, monoacetate (L-NMMA) and L-arginine were purchased from Calbiochem (La Jolla, CA). BRL 37344 (4-[-[2hydroxy-(3-chlorophenyl)ethyl-amino]propyl] phenoxyacetate) was obtained from Research Biochemicals Int. (Natick, MA). Bupranolol was a gift from Schwarz Pharma (Monheim, Germany).

Contractility measurements. Tissues were placed in a transport solution containing $(\mathrm{mM}) 120 \mathrm{NaCl}, 5 \mathrm{KCl}, 1 \mathrm{CaCl}_{2}, 1.1 \mathrm{MgCl}_{2}, 0.33$ $\mathrm{NaH}_{2} \mathrm{PO}_{4}, 5$ glucose, and 10 Hepes ( $\mathrm{pH}$ being adjusted to 7.4 with $\mathrm{NaOH}$ ) and quickly conveyed to the laboratory. Preparations were then placed in an experimental chamber and superfused at a flow rate of $5 \mathrm{ml} /$ min with oxygenated $\left(95 \% \mathrm{O}_{2}, 5 \% \mathrm{CO}_{2}\right)$ Tyrode's solution $\left(37 \pm 0.5^{\circ} \mathrm{C}\right)$ composed as follows (mM): $120 \mathrm{NaCl}, 5 \mathrm{KCl}, 2.7 \mathrm{CaCl}_{2}, 1.1 \mathrm{MgCl}_{2}, 0.33$ $\mathrm{NaH}_{2} \mathrm{PO}_{4}, 5$ glucose, and $27 \mathrm{NaHCO}_{3}$. Tissues were subjected to field stimulation at a frequency of $0.6 \mathrm{~Hz}$. Stimulus pulse width was $1-2 \mathrm{~ms}$, and amplitude was twice the diastolic threshold. Tension was recorded using a mechanoelectric force transducer (Akers, AE 801; SensoNor, Horten, Norway), as described previously (13). After a 60-min equilibration period, the cumulative dose-response curves of $\beta_{3}$-adrenoceptor agonists were determined by superfusion with successive increasing concentrations of the drugs. For all concentrations, tension was measured at steady state using a digital storage oscilloscope (model 400; Gould, Les Ullis, France), a strip chart recorder (model 8188; Gould), and a digital tape recorder (model DTR-1200; Biologic, Claix, France).

cGMP assay. Frozen heart samples were weighed and homogenized by Polytron in ice-cold $6 \%$ TCA. After centrifugation at 1,000 $\mathrm{g}$ for $10 \mathrm{~min}$ at $4^{\circ} \mathrm{C}$, TCA was extracted by washing the supernatants five times with $250 \mu$ l of water-saturated ether. The remaining ether was evaporated overnight, and cGMP contents were measured using an enzyme immunoassay kit (Biotrak; Amersham Life Science, Arlington Heights, IL). Absorbance was read on a spectrophotometer (SLT-Spectra microplate reader; SLT Labinstruments GmbH, Salzburg, Austria) at $450 \mathrm{~nm}$. A standard relation curve was drawn for each experiment. The mean value was calculated from duplicate measurements of each sample.

Measurements of $\mathrm{NO}$ production. For the experiments involving NO measurement, endomyocardial biopsies were incubated in ex- actly $0.5 \mathrm{ml}$ of Tyrode's solution. NO production in the organ bath was measured using an electrochemical sensor (WPI, Sarasota, FL). $50-\mu l$ aliquots of Tyrode's solution containing the contracting endomyocardial biopsies were mixed with $150 \mu \mathrm{l}$ of $\mathrm{H}_{2} \mathrm{SO}_{4} / \mathrm{KI}$ in 96-well plates in which the tip of the sensor was immersed. $\mathrm{NO}$ was generated equimolarly from nitrite, according to the reaction $2 \mathrm{KNO}_{2}+2 \mathrm{KI}+$ $2 \mathrm{H}_{2} \mathrm{SO}_{4} \rightarrow 2 \mathrm{NO}+\mathrm{I}_{2}+2 \mathrm{H}_{2} \mathrm{O}+2 \mathrm{~K}_{2} \mathrm{SO}_{4}$ (Eq. 1), and oxidized at the tip of the electrochemical sensor to generate an oxidation current proportional to the concentration of NO in each aliquot. Before measurements, the electrode was calibrated under identical experimental conditions (i.e., temperature, volume of sample covering the sensor tip) using the same chemical generation of $\mathrm{NO}$ as above (Eq. 1) with known concentrations of $\mathrm{KNO}_{2}$. Control aliquots of freshly prepared Tyrode's solution (as in the contractility experiments) showed no background current suggestive of electroactive components in the solution. Similarly, no signal was detected when the sensor was immersed in Tyrode's solution not conditioned by any tissue but to which BRL 37344 (up to $1 \mu \mathrm{M}$ ), L-NMMA (at $1 \mathrm{mM}$ ), or both had been added.

To determine the NO produced by the endomyocardial biopsies, aliquots of Tyrode's solution were taken sequentially from the organ bath after the initial equilibration period under control conditions and $10 \mathrm{~min}$ after the addition of BRL $37344(1 \mu \mathrm{M})$ with or without L-NMMA $(10 \mu \mathrm{M})$. Absolute concentrations of NO were measured in both conditions and the results were expressed as increases in NO over baseline for each biopsy.

Immunohistochemical analysis of NOS. Immunohistochemical localization of eNOS and iNOS was performed on cryostat sections of snap-frozen human endomyocardial biopsies using a previously described method (7). A specific mouse monoclonal antibody to eNOS (Transduction Labs, Lexington, KY), and two mouse monoclonal (clones 6 and 54; Transduction Labs) and three rabbit polyclonal (Transduction Labs; ABR, Golden, CO; and Biomol, Plymouth Meeting, PA) antibodies to iNOS were used as primary antibody, followed by detection with an avidin-biotin complex immunoperoxidase method and localization using diaminobenzidine as chromogen. Control experiments were run in parallel with normal mouse $\mathrm{IgG}$ as primary antibody.

Duplicate sections were also examined independently for histological signs of immune rejection and a score of rejection was assigned on a scale of 1 to 3 , with 3 representing the maximal severity of rejection.

Statistics. Results are expressed as the mean \pm SEM of $n$ experiments. The statistical significance of the drug effect was assessed using one-way ANOVA followed by a Dunnett test. Comparison of the different dose-response curves was performed by two-way ANOVA.

\section{Results}

Negative inotropic effect of $\beta_{3}$-adrenoceptor stimulation: effect of methylene blue. BRL 37344, a $\beta_{3}$-adrenoceptor agonist, induced a dose-dependent negative inotropic effect at concentrations ranging from $0.1 \mathrm{nM}$ to $1 \mu \mathrm{M}$ (Fig. $1, A$ and $C$ ). The $\mathrm{pD}_{2}$ value was $8.41 \pm 0.21(n=7)$. The maximum effect obtained at a concentration of $1 \mu \mathrm{M}$ decreased peak tension by $55.7 \pm 3.7 \%(P<0.01, n=7)$ below the control level. This decrease in peak tension was associated with an abbreviation of the twitch. At $1 \mu \mathrm{M}, \mathrm{BRL} 37344$ decreased total twitch duration from $532 \pm 45$ to $463 \pm 38 \mathrm{~ms}(P<0.01, n=7)$, time-topeak from $191 \pm 18$ to $169 \pm 17 \mathrm{~ms}(P<0.01, n=7)$, half-contraction time from $81 \pm 7$ to $72 \pm 7 \mathrm{~ms}(P<0.01, n=7)$, and half-relaxation time from $150 \pm 12$ to $123 \pm 11 \mathrm{~ms}(P<0.01$, $n=7)$.

The dose-response curve of BRL 37344 was then performed in the presence of methylene blue $(10 \mu \mathrm{M})$, an agent that inhibits activation of soluble guanylyl cyclase by NO in 
A

B
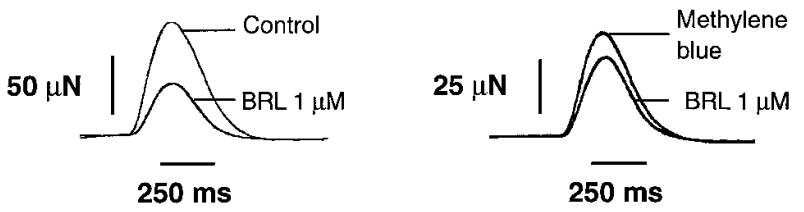

C

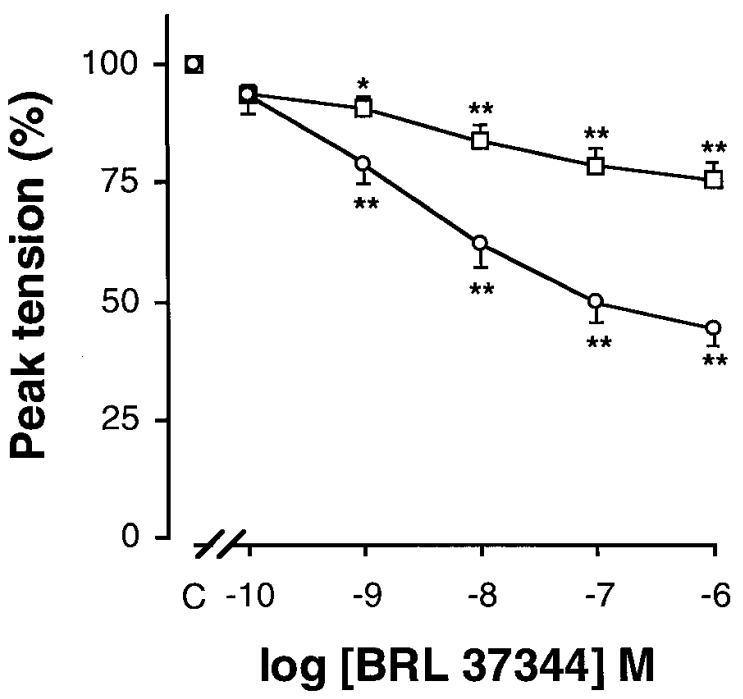

Figure 1. The effects of methylene blue on the negative inotropic response to BRL $37344(B R L)$ in human endomyocardial biopsies. Biopsies were perfused with regular Tyrode's solution or Tyrode's solution containing methylene blue $(10 \mu \mathrm{M})$ until a stable baseline contraction was obtained (20 min; control $[A]$ and methylene blue $[B]$, respectively). Cumulative concentrations of BRL were then perfused either in control solution or in solution containing methylene blue. BRL was perfused for $10 \mathrm{~min}$ at each concentration to obtain a steady-state effect. $(A)$ Superimposed twitches obtained with control solution at baseline and after $1 \mu \mathrm{M}$ BRL perfusion. (B) Representative twitches obtained after 20-min perfusion of methylene blue $(10 \mu \mathrm{M})$ alone and in the presence of $1 \mu \mathrm{M}$ BRL. (C) Dose-response curves for the negative inotropic effect of BRL alone and in the presence of $10 \mu \mathrm{M}$ methylene blue. Values are the means \pm SEM of seven experiments for BRL (circles) and eight experiments for BRL plus methylene blue (boxes). Response is expressed as the percentage of peak tension measured at baseline. ${ }^{*} P<0.05$ vs. control and ${ }^{* *} P<0.01$ vs. control.

various biological systems $(14,15)$. A 30-min pretreatment of methylene blue alone had no significant effect on basal peak tension $(52.4 \pm 8.8$ and $49.7 \pm 9.1 \mu \mathrm{N}$ in control and methylene blue-treated biopsies, respectively; $n=8$ ). However, the negative inotropic effect of the $\beta_{3}$-adrenoceptor agonist was strongly reduced in the presence of this agent $(P<0.01$ vs. BRL 37344 alone; Fig. 1, $B$ and $C$ ). In these conditions, $1 \mu \mathrm{M}$ BRL 37344 decreased peak tension by only $24.4 \pm 3.7 \%(P<$ 0.01 vs. control, $n=8$ ), and the effects on twitch time course were abolished. The $\mathrm{pD}_{2}$ value for BRL 37344 was not modified by pretreatment with methylene blue $(8.41 \pm 0.32, n=8)$.

Effect of NOS inhibitors on the response of human ventricular muscle to $\beta_{3}$-adrenoceptor stimulation. To characterize the involvement of an NOS pathway in the negative inotropic effect of $\beta_{3}$-adrenoceptor stimulation, we determined whether the NOS inhibitors, L-NAME and L-NMMA, modified the contractile response to BRL 37344. None of these compounds had any significant effect on the basal peak tension of human endomyocardial biopsies after a 20 -min pretreatment $(87.0 \pm$ 19.7 and $82.8 \pm 18.3 \mu \mathrm{N}$ in control and $100 \mu \mathrm{M}$ L-NAME, respectively, $n=9 ; 191.3 \pm 26.7$ and $185.6 \pm 26.7 \mu \mathrm{N}$ in control and $10 \mu \mathrm{M}$ L-NMMA, respectively; $n=5$ ). As illustrated in Fig. 2, these NOS inhibitors markedly attenuated the dosedependent effects of the $\beta_{3}$-adrenoceptor agonist without modifying its $\mathrm{pD}_{2}$ value significantly $(8.11 \pm 0.28, n=9$ and $7.77 \pm 0.22, n=5$ in the presence of L-NAME and L-NMMA, respectively). A 20-min pretreatment of endomyocardial biopsies with L-NAME $(100 \mu \mathrm{M})$ or L-NMMA $(10 \mu \mathrm{M})$ reduced the negative inotropic effect of $1 \mu \mathrm{M}$ BRL 37344 to $-21.9 \pm$
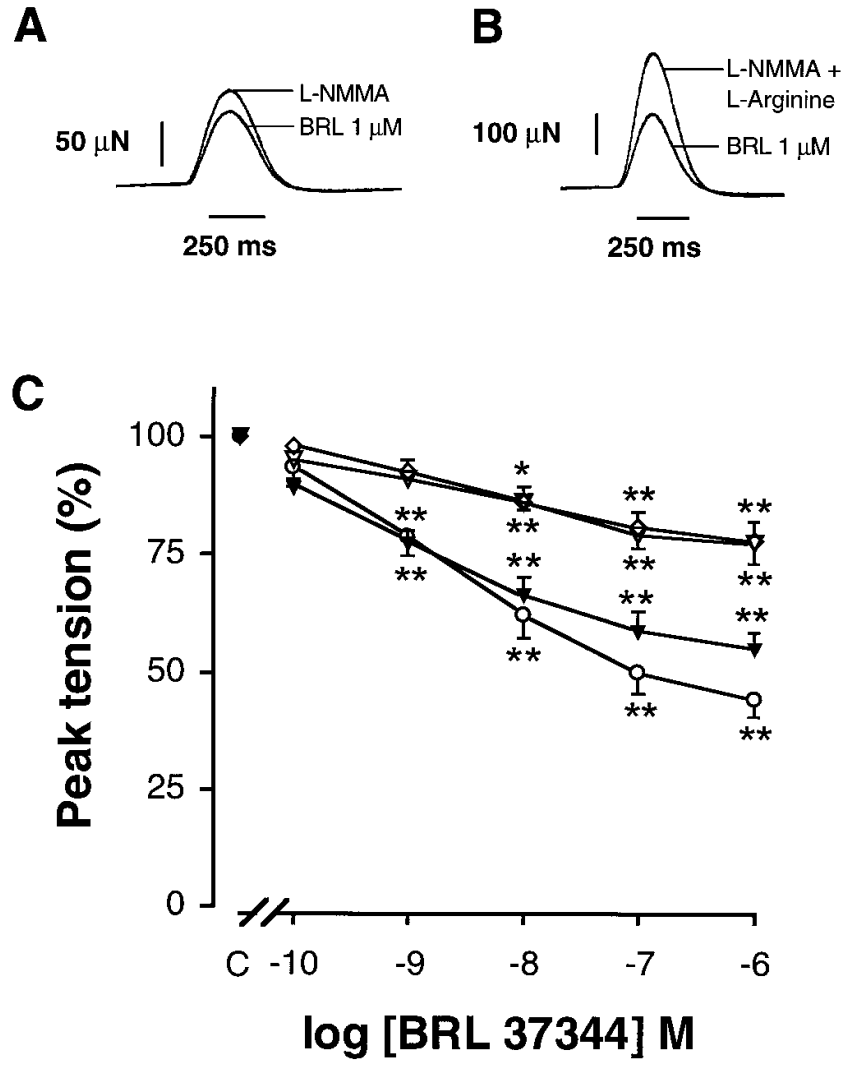

Figure 2. Dose-response curves for the negative inotropic effect of BRL $37344(B R L)$ in the presence of the NOS inhibitors, L-NMMA and L-NAME, in human endomyocardial biopsies. Biopsies were perfused with regular Tyrode's solution or Tyrode's solution containing the NOS inhibitors until a stable baseline contraction was obtained (20 min). Cumulative concentrations of BRL were then perfused in the absence or the presence of the NOS inhibitors. BRL was perfused for $10 \mathrm{~min}$ at each concentration to obtain a steady-state effect. (A) Superimposed twitches obtained after pretreatment with $10 \mu \mathrm{M}$ L-NMMA and in the presence of L-NMMA plus $1 \mu \mathrm{M}$ BRL. (B) Superimposed twitches obtained in the presence of $10 \mu \mathrm{M}$ L-NMMA plus $3 \mathrm{mM}$ L-arginine, the substrate for NOS, before and after addition of $1 \mu \mathrm{M}$ BRL. $(C)$ Dose-response curves for the effect of BRL 37344 alone (circles, $n=7$ ), in the presence of $100 \mu \mathrm{M}$ L-NAME (diamonds, $n=9$ ), in the presence of $10 \mu \mathrm{M} \mathrm{L-NMMA}$ (open triangles, $n=5$ ), and in the presence of $10 \mu \mathrm{M} \mathrm{L}-\mathrm{NMMA}$ plus 3 $\mathrm{mM} \mathrm{L}$-arginine (filled triangles, $n=5$ ). For all curves, values are the means \pm SEM of $n$ experiments. $* P<0.05$ vs. control and $* * P<0.01$ vs. control. 
$4.1 \%(n=9)$ and $-22.6 \pm 4.3 \%(n=5)$ of control values, respectively ( $P<0.01$ vs. BRL 37344 alone). As with methylene blue, these inhibitors abolished the effects of BRL 37344 on the twitch time course.

Reversal of the effect of NOS inhibitors on $\beta_{3}$-adrenoceptor stimulation with L-arginine. In further studies to ascertain the specificity of L-NMMA and L-NAME effects on NO synthesis, we tested the reversibility of their action using an excess of either L-arginine, the substrate for NOS, or its enantiomer, $\mathrm{D}$-arginine. The addition of $3 \mathrm{mM} \mathrm{D}$-arginine, which is not used as a substrate by NOS, did not modify the inhibitory effect of L-NMMA on $\beta_{3}$-adrenoceptor stimulation (data not shown). At the same concentration, L-arginine alone marginally reduced basal peak tension $(285.0 \pm 41.1$ and $257.9 \pm 50.7 \mu \mathrm{N}$ in control and L-arginine-treated biopsies, respectively; $n=5$; $P$ was not significant). However, in the presence of both L-NMMA $(10 \mu \mathrm{M})$ and L-arginine $(3 \mathrm{mM})$ in the superfusion solution, the negative inotropic effect of $\beta_{3}$-adrenoceptor stimulation was partially restored (Fig. $2, B$ and $C ; P<0.05$ vs. L-NMMA). In the latter condition, $1 \mu \mathrm{M}$ BRL 37344 decreased peak tension by $45.2 \pm 3.8 \%(P<0.01$ vs. control, $n=5)$.

$\beta_{3}$-adrenergic effects of norepinephrine. All experiments with norepinephrine were done in the presence of prazosine (1 $\mu \mathrm{M})$. Under these conditions, norepinephrine $(n=8)$ induced a dose-dependent increase in contractility $\left(\mathrm{pD}_{2}=6.24 \pm 0.23\right)$ and produced an acceleration of the twitch. At the concentration producing the maximal effect $(7 \mu \mathrm{M})$, norepinephrine increased peak tension by $244 \pm 27 \%(P<0.01)$ and accelerated the twitch, decreasing total duration from $460 \pm 19$ to $419 \pm 21 \mathrm{~ms}(P<0.01)$, time-to-peak from $166 \pm 10$ to $139 \pm 5 \mathrm{~ms}$ $(P<0.01)$, half-contraction time from $74 \pm 6$ to $65 \pm 3 \mathrm{~ms}(P<$ $0.05)$, and half-relaxation time from $109 \pm 8$ to $88 \pm 4 \mathrm{~ms}(P<$ $0.01)$. In the presence of both prazosine and $10 \mu \mathrm{M}$ nadolol, a potent $\beta_{1}$ - and $\beta_{2}$-adrenoceptor antagonist, the positive inotropic effect of norepinephrine was inverted to a negatively inotropic effect. Under these conditions, norepinephrine decreased contractility at concentrations ranging from 0.7 to $10 \mu \mathrm{M}$ $\left(\mathrm{pD}_{2}=5.70 \pm 0.14 ; n=11\right)$. At $10 \mu \mathrm{M}$ norepinephrine, peak tension was decreased by $37.9 \pm 5.7 \%(P<0.01)$. This effect was associated with a reduction in total twitch duration from $532 \pm 21$ to $509 \pm 22 \mathrm{~ms}(P<0.05)$, time-to-peak from $188 \pm 10$ to $177 \pm 10 \mathrm{~ms}(P<0.01)$, half-contraction time from $76 \pm 4$ to $69 \pm 5 \mathrm{~ms}(P<0.05)$, and half-relaxation time from $147 \pm 9$ to $138 \pm 9 \mathrm{~ms}(P<0.01)$. Importantly, this negative inotropic effect was also attenuated after NOS inhibition (Fig. 3, inset). After 20 min of pretreatment with $10 \mu \mathrm{M}$ L-NMMA, $10 \mu \mathrm{M}$ norepinephrine in the presence of nadolol decreased peak tension only by $23 \pm 3 \%$ ( $n=6, P<0.05$ vs. norepinephrine plus nadolol in the absence of L-NMMA).

Effect of $\beta_{3}$-adrenergic stimulation on $\mathrm{NO}$ production in human endomyocardial biopsies. Baseline production of NO in the absence of agonist resulted in concentrations ranging from 378 to $4,180 \mathrm{nmol} /$ liter of NO in the organ bath $(n=9)$. In four biopsies obtained from four different patients, BRL $37344(1 \mu \mathrm{M})$ increased NO production by $218 \pm 16 \%$ over baseline levels (patients $1-4$, see Fig. $4 A$ ). No increase was observed with BRL 37344 in two biopsies from other patients, and another did not respond to either BRL 37344, acetylcholine, or isoproterenol (each at $1 \mu \mathrm{M}$, data not shown). In two additional biopsies from the patients who responded to the $\beta_{3}$-adrenoceptor agonist (patients 1 and 2), preincubation with $10 \mu \mathrm{M}$ L-NMMA abolished the increase with BRL 37344 (Fig. 4 A).

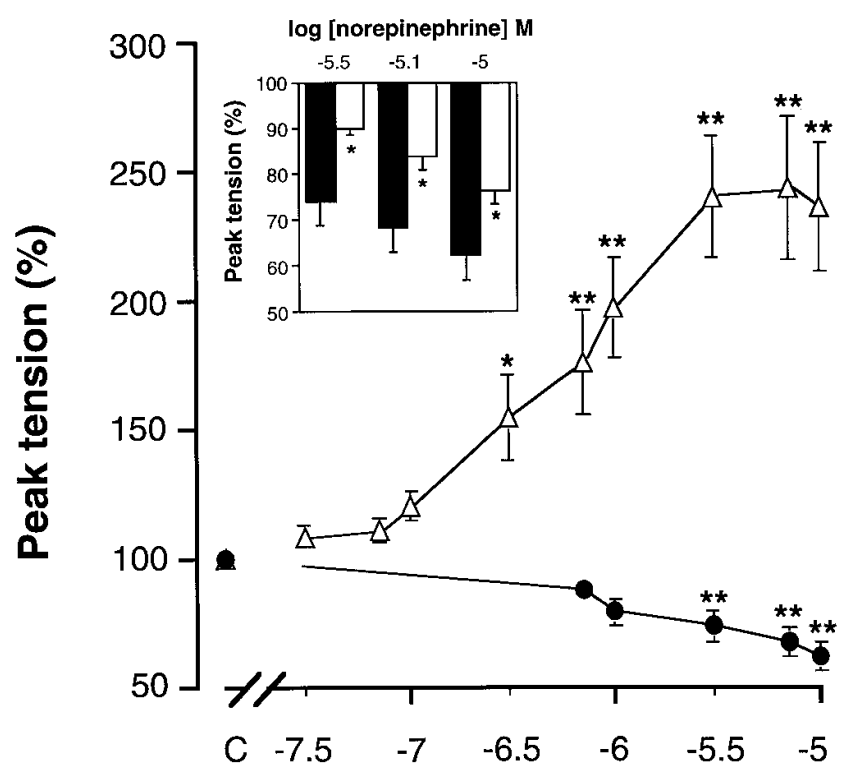

$\log$ [norepinephrine] $\mathrm{M}$

Figure 3. Effects of L-NMMA on the $\beta_{3}$-adrenergic action of norepinephrine. All experiments were performed in the presence of $1 \mu \mathrm{M}$ prazosine. Dose-response curves were determined for the inotropic effects of norepinephrine performed on peak tension of human endomyocardial biopsies in the absence (open triangles, $n=8$ ) or in the presence of $10 \mu \mathrm{M}$ nadolol (filled circles, $n=11$ ). In the insert, bar graphs represent the negative inotropic effect of norepinephrine plus nadolol in the absence (filled bars, $n=11$ ) and in the presence of $10 \mu$ M L-NMMA (hollow bars, $n=6$ ). Values are the means \pm SEM of $n$ experiments. ${ }^{*} P<0.05$ vs. control and $* * P<0.01$ vs. control.

Effect of $\beta_{3}$-adrenoceptor stimulation on NOS-dependent intracellular cGMP levels. Intracellular cGMP levels were determined in human endomyocardial biopsies in experimental conditions identical to those used in contractility studies (Fig. 4 $B)$. Superfusion with $1 \mu \mathrm{M}$ BRL 37344 produced a significant increase in cGMP above control levels (control $=0.048 \pm$ $0.023 ; n=7$; BRL $37344=0.147 \pm 0.031 \mathrm{fmol} / \mathrm{mg}$ wet weight, $n=$ 11; $P<0.05$ vs. control). The effect of BRL 37344 on cGMP levels was abolished by pretreatment of the biopsies with 10 $\mu$ M L-NMMA $(0.077 \pm 0.025 \mathrm{fmol} / \mathrm{mg}$ wet weight; $n=7 ; P<$ 0.05 vs. BRL 37344 alone) or $100 \mu \mathrm{M}$ L-NAME (0.024 \pm 0.005 fmol/mg wet weight; $n=6 ; P<0.05$ vs. BRL 37344 alone). Addition of $3 \mathrm{mM}$ L-arginine to $10 \mu \mathrm{M}$ L-NMMA completely restored the effect of BRL 37344 on cGMP levels (0.142 \pm $0.031 \mathrm{fmol} / \mathrm{mg}$ wet weight; $n=6)$. Isoproterenol $(1 \mu \mathrm{M})$, a nonselective $\beta_{1^{-}}, \beta_{2^{-}}$, and $\beta_{3^{-}}$-adrenoceptor agonist, produced an increase in cGMP level comparable to that of the preferential $\beta_{3}$-adrenoceptor agonist, BRL 37344 (0.174 $\pm 0.076 \mathrm{fmol} /$ mg wet weight; $n=6 ; P<0.05$ vs. control). To further ascertain the specificity of the effect of BRL 37344 on $\beta$-adrenoceptor stimulation for the observed increase in NO and cGMP production, we examined the effect of the $\beta$-adrenoceptor antagonist, bupranolol, on the NO-dependent cGMP increases in human biopsies (Fig. 4 C). The BRL 37344-induced increase in cGMP $(309 \pm 65 \%$ above control level; $n=11 ; P<0.05$ vs. control), which was markedly reduced after pretreatment with $10 \mu \mathrm{M}$ L-NMMA $(163 \pm 52 \% ; n=7 ; P<0.05$ vs. BRL 37344 alone) was also inhibited in the presence of the $\beta_{1-3^{-}}$ 
A

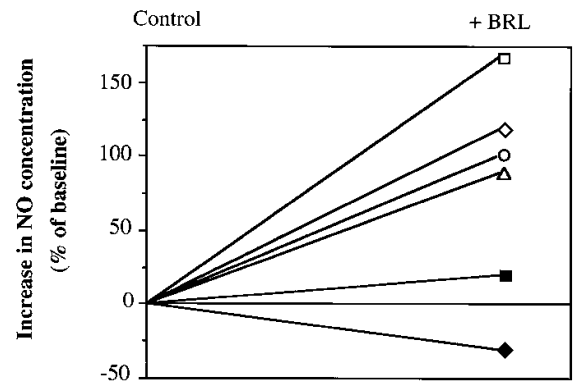

B

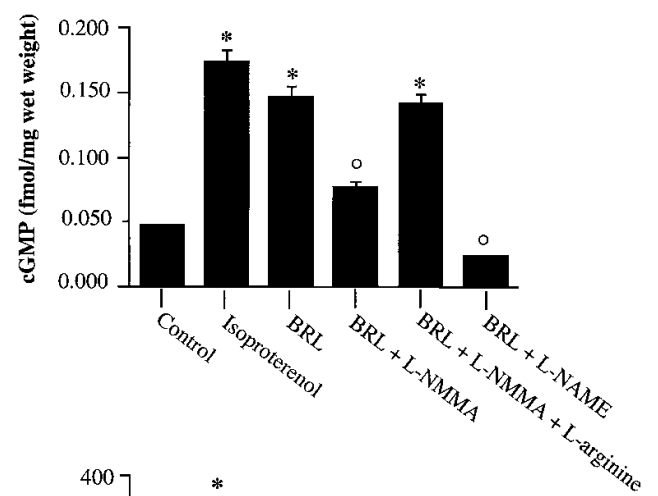

C

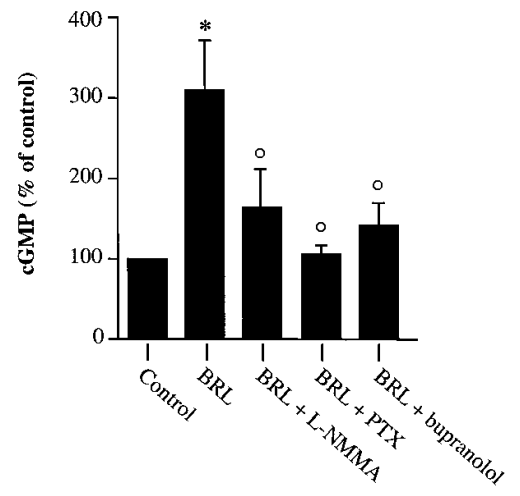

Figure 4. (A) Increase in NO production in human endomyocardial biopsies induced by a $\beta_{3}$-adrenoceptor agonist. An electrochemical sensor was used to measure NO production in the organ bath from electrically stimulated $(0.6 \mathrm{~Hz})$, contracting human ventricular endomyocardial biopsies, as described in Methods. Treatment with BRL $37344(1 \mu \mathrm{M})$ resulted in an increase in NO production from 88 to $165 \%$ over baseline levels in biopsies from four different patients (patient 1, open square; patient 2, open diamond; patient 3, open circle; patient 4, open triangle). In two additional biopsies from patients 1 (filled square) and 2 (filled diamond), pretreatment with the NOS inhibitor L-NMMA $(10 \mu \mathrm{M})$ abolished the NO increase with BRL 37344. ( $B$ and $C$ ) Increase in cGMP contents of human endomyocardial biopsies treated with $\beta$-adrenoceptor agonists. Cumulative doseresponse curves were performed for the contractile effect of each agonist. cGMP contents were measured at the concentration producing the maximal contractile effect. (B) The effect of BRL 37344 (BRL) was analyzed in the absence or presence of the NOS inhibitors, L-NMMA and L-NAME. The reversibility of the inhibitory effect of these compounds was tested in the presence of an excess of L-arginine ( $3 \mathrm{mM})$. Bar graphs represent cGMP contents measured in Tyrode's solution (control, $n=7$ ); after addition of $1 \mu \mathrm{M}$ isoproterenol $(n=6)$; or $1 \mu \mathrm{M}$ BRL 37344 alone $(B R L, n=11)$; or BRL 37344 in the presence of $10 \mu \mathrm{M}$ L-NMMA $(n=7)$; and BRL 37344 in the presence of $10 \mu \mathrm{M} \mathrm{L}-\mathrm{NMMA}$ plus $3 \mathrm{mM} \mathrm{L}$-arginine $(n=6)$; or BRL 37344 in the presence of $100 \mu \mathrm{M}$ L-NAME $(n=6)$. $(C)$ Bar graphs represent the intracellular cGMP levels expressed as percentage of control levels in biopsies treated with BRL 37344 (BRL) alone $(n=$ adrenoceptor antagonist bupranolol $(1 \mu \mathrm{M} ; 141 \pm 33 \% ; n=6$; $P<0.05$ vs. BRL 37344 alone). Finally, pretreatment of human biopsies with $0.5 \mu \mathrm{g} / \mathrm{ml}$ pertussis toxin, a concentration which we had shown previously to abolish the negative inotropic effect of BRL 37344 (1), also fully inhibited the increase in cGMP with the same concentration $(1 \mu \mathrm{M})$ of BRL 37344 ( $105 \pm 14 \% ; n=5 ; P<0.05$ vs. BRL 37344 alone).

Immunodetection of eNOS and iNOS in human ventricular muscle. The rejection score (RS) of the biopsy specimens ranged from 0 to $1(\mathrm{RS}=0: 76 \% ; \mathrm{RS}=0.5: 18 \%$; and $\mathrm{RS}=1$ : $6 \% ; n=54)$. A monoclonal antibody directed against human eNOS was used for immunohistochemical localization of eNOS in human ventricular muscle (Fig. 5). No staining was detectable above background when the primary antibody was omitted or nonspecific mouse myeloma IgG was used. With the eNOS-specific antibody, a strong signal was detected in endothelial cells from the microvasculature and the endocardial layer. In addition, a distinct signal was observed in cardiac myocytes. No other cell type stained positively. We have also used several anti-iNOS antibodies that have been reported to cross to or become directed against human iNOS. With all five reagents, no specific labeling of the cardiac myocytes or endothelial cells was observed in any of five biopsies tested (data not shown).

\section{Discussion}

Our study demonstrates that $\beta_{3}$-adrenoceptor stimulation decreases human cardiac contractility through activation of an NOS pathway. This conclusion is based on several lines of evidence. The effect of a $\beta_{3}$-adrenoceptor agonist, BRL 37344, on contraction was inhibited both by a nonspecific NO blocker, methylene blue, and two different NOS inhibitors, L-NAME and L-NMMA. The latter also inhibited the negative inotropic effect of the naturally occurring norepinephrine in the presence of both $\alpha_{1}$ - and $\beta_{1-2}$-adrenoceptor blockade. Moreover, increases in NO production and intracellular cGMP levels were observed in similar preparations after treatment with the $\beta_{3}$-adrenoceptor agonist. These increases were also inhibited by NOS inhibitors and by bupranolol, a $\beta_{1-3}$-adrenoceptor antagonist. Finally, immunohistochemical analysis revealed the presence of abundant eNOS but not iNOS proteins in sections of human endomyocardial biopsies, suggesting that the NOS isoform involved in the inotropic effect of $\beta_{3}$-adrenoceptor stimulation is probably eNOS.

The effects of L-arginine analogues on contractile response to $\beta_{3}$-adrenoceptor stimulation were specifically due to NOS inhibition since they could be reversed by an excess of L-arginine, the natural substrate for the enzyme, whereas D-arginine, its enantiomer, was inactive. A similar reversal with L-arginine was observed for L-NMMA inhibition of the increases in cGMP induced by $\beta_{3}$-adrenoceptor stimulation. Moreover, none of these inhibitors, when applied alone, induced any change in basal muscle tension suggestive of unspecific contractile effect, or modified the $\mathrm{pD}_{2}$ values for BRL 37344, rul-

11) and in the presence of $10 \mu \mathrm{M}$ L-NMMA $(n=7), 0.5 \mu \mathrm{g} / \mathrm{ml}$ pertussis toxin $(P T X, n=5)$, and $1 \mu \mathrm{M}$ bupranolol $(n=6)$. The values given for each condition represent the mean of $n$ individual experiments (SEM is indicated by bars). ${ }^{*} P<0.05$ vs. control, ${ }^{\circ} P<0.05$ vs. BRL 37344 . 


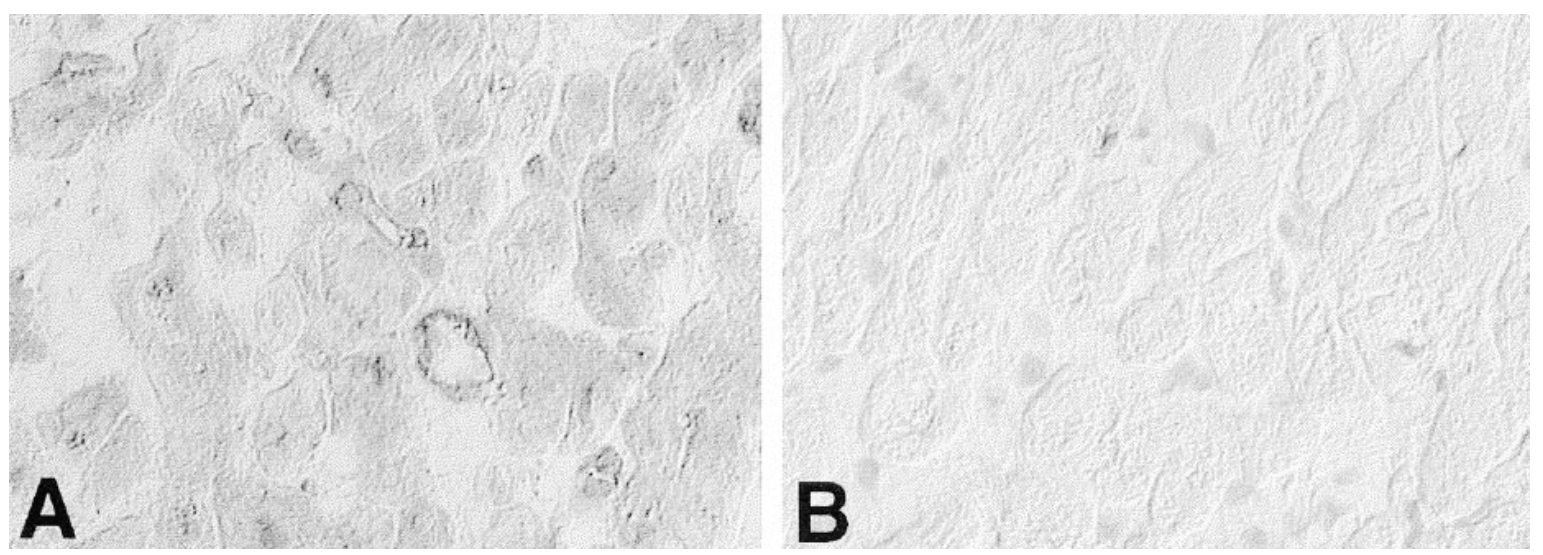

Figure 5. Immunodetection of eNOS in human endomyocardial biopsies. (A) Immunohistochemical analysis of human endomyocardial biopsy shows the immunoreactivity of anti-eNOS in vascular endothelium and in cardiac myocytes. $(B)$ Myocyte minimal background staining is seen with control mouse IgG. $\times 200$, original magnification.

ing out unspecific interactions at the receptor level. Direct measurements with an NO-specific microsensor showed that increases in $\mathrm{NO}$ production with the $\beta_{3}$-adrenoceptor agonist were also inhibited by L-NMMA.

In a previous study (1), we had demonstrated that the classical positive inotropic effect of isoproterenol was inverted to a negative inotropic effect in the presence of nadolol (1), a $\beta_{1^{-}}$ and $\beta_{2}$-adrenoceptor antagonist with a low affinity for $\beta_{3^{-}}$ adrenoceptors $(16,17)$. This suggested the presence of functional $\beta_{3}$-adrenoceptors in human ventricular muscle, which was confirmed by the detection of mRNA specific for the $\beta_{3^{-}}$ adrenoceptor subtype. This receptor is distinct from atypical $\beta$-adrenoceptor(s) described in cardiac tissue from some mammalian species or in human atria which, when stimulated by nonconventional partial agonists such as pindolol, oxprenolol, and CGP 12177, produce(s) cardiostimulatory effects (18-20). Currently, this atypical pharmacological response is considered to be mediated by a fourth $\beta$-adrenoceptor $(21,22)$ for which characterization of a full-length cDNA is still lacking. Negative inotropic effects were also obtained with several $\beta_{3^{-}}$ adrenoceptor agonists, including BRL 37344 used in this study, with the following order of potency: BRL $37344>$ SR $58611<$ CL $316243>$ CGP 12177 (1). Importantly, we now show that the effect of BRL 37344 can be reproduced with the naturally occurring catecholamine, norepinephrine, at concentrations close to pathophysiologically relevant levels. The unveiling of the negative inotropic effect after blockade of the $\alpha_{1^{-}}$and $\beta_{1-2^{-}}$ adrenoceptors with prazosine and nadolol, respectively, most likely identifies it as a $\beta_{3}$-adrenoceptor effect.

The involvement of $\mathrm{NO}$ in the negative inotropic action after $\beta_{3}$-adrenoceptor stimulation is consistent with the effects of NO endogenously produced by eNOS in ventricular myocytes from several species $(7,9,23)$. In ventricular myocytes from adult rats, inhibition of eNOS with L-NAME resulted in a potentiation of the contractile response of these cells to isoproterenol, a nonspecific $\beta$-adrenoceptor agonist, suggesting that NO produces a countervailing action on the positive inotropic effect of catecholamines in the heart. Interestingly, eNOS inhibition in the absence of catecholamine had no detectable effect on baseline contractility of rat myocytes (9), which is consistent with our results on the contraction of human endomyocardial biopsies in this study. Quantitatively similar results have been found in the in situ canine heart, in which an intracoronary infusion of L-NAME increased the maximum rate of rise of left ventricular pressure $(\mathrm{dP} / \mathrm{dtmax})$ in response to infusions of either dobutamine or isoproterenol (10). These results in animal models have been reproduced in patients with left ventricular dysfunction in whom increases in left ventricular $\mathrm{dP} / \mathrm{dt}$ in response to infusions of dobutamine were improved by intracoronary L-NMMA (24). Taken together, these findings indicate that catecholamines activate both positively inotropic and negatively inotropic pathways in human ventricular muscle as shown in this work with norepinephrine in the presence or absence of nadolol. This is best rationalized in terms of the concurrent activation of several populations of adrenoceptors, with $\beta_{1}$ - and $\beta_{2}$-adrenoceptors mediating the classical positive inotropic effect while $\beta_{3}$-adrenoceptors mediate (perhaps not exclusively) a negative inotropic effect through NOS activation. Therefore, the net effect of the adrenergic input on cardiac inotropism is likely to be influenced by changes in the expression and coupling of each adrenoceptor subtype relative to the others, which are known to be differentially regulated in pathological conditions (25). In this regard, it is worth noting that these studies were undertaken in denervated hearts which may not entirely reflect the biology of a normal myocardium. However, under our experimental conditions we did not detect significant expression of iNOS, which is also consistent with the absence of histological signs of transplant rejection in our samples. These observations suggest that $\beta_{3}$-adrenoceptor agonists increase $\mathrm{NO}$ production either through direct activation of a constitutively expressed NOS, most likely eNOS, or possibly through acute increases in L-arginine transport supplying the substrate for the enzyme. The regulation of the expression of $\beta_{3}$-adrenoceptors and eNOS in failing hearts is the object of ongoing studies in our laboratories.

The NO-mediated negative inotropic effect may involve several intracellular mechanisms. The observation that $\beta_{3^{-}}$ adrenoceptor stimulation and NO production are accompanied by increases in intracellular cGMP levels supports a role for this cyclic nucleotide in mediating the attenuation of cardiac muscle contraction. Intracellular pathways that may downregulate cardiac contractility in response to cGMP elevation include activation of cGMP-dependent protein kinases, which decrease calcium current through regulation of L-type 
calcium channels $(26,27)$ or decrease cardiac myofilament sensitivity to calcium (28) (possibly through phosphorylation of troponin I), and the activation of cGMP-stimulated phosphodiesterases (PDE II; 29) which decrease cAMP levels (30). Alternatively, NO may regulate cardiac function in a cGMPindependent manner through covalent modifications of key proteins such as cytochrome $c$ oxidase (31), creatine phosphokinase (32), or L-type calcium channel (33). However, evidence from previous reports suggests that the relative importance of each pathway as well as the final effect on contractility may be profoundly influenced by parameters such as the experimental preparation, species, and region of the heart studied, as well as the concentration of NO or cGMP generated (for reviews see references 4 and 5). Interestingly, L-type calcium currents and contraction, which were increased by catecholamine stimulation in rat ventricular myocytes, were attenuated by muscarinic receptor stimulation through a mechanism involving both eNOS activation (34) and $\mathrm{G}_{0}$ proteins (35). Similarly, pretreatment of human ventricular biopsies with pertussis toxin abolished the effect of $\beta_{3}$-adrenoceptor stimulation both on cardiac contraction in our previous study (1) and on cGMP generation in this work (Fig. 4C), suggesting the involvement of a $\mathrm{G}_{\mathrm{i} / 0}$ protein (1). A more complete characterization of the $G$ protein-mediated coupling of the $\beta_{3^{-}}$ adrenoceptor to eNOS activation in ventricular cells will await the results of further experiments which are currently ongoing.

In conclusion, this work demonstrates that $\beta_{3}$-adrenoceptor stimulation decreases human cardiac contractility through activation of an NOS pathway. These results may have considerable implications in our understanding of the pathophysiology of heart failure. This disease is characterized by high adrenergic tone and impaired $\beta$-adrenergic responsiveness, resulting in part from a downregulation of $\beta_{1^{-}}$and $\beta_{2}$-adrenoceptors. Unlike the $\beta_{1}$ - and $\beta_{2}$-subtypes, $\beta_{3}$-adrenoceptors lack regulatory phosphorylation sites for $\mathrm{G}$ protein receptor kinases (36) and could be relatively resistant to agonist-induced desensitization. Future work will be needed to identify the functional consequences of the alterations in the balance between opposing inotropic influences of these $\beta$-adrenoceptor subtypes in the failing human heart.

\section{Acknowledgments}

We thank Ms. Karine Laurent and Mr. Mortéza Erfanian (INSERM 96-01) for skillful technical assistance, Drs. Hervé L'Henaff and Thierry Petit from the Department of Cardiology (Nantes University Hospital) for providing the human endomyocardial biopsies, and Dr. Denis Escande (INSERM 96-01) for helpful advice.

This work was supported by grants from the INSERM and the Fédération Française de Cardiologie (C. Gauthier and H. Le Marec), the National Institutes of Health (L. Kobzik), and an Action de Recherche Concertée and Belgian National Fund for Scientific Research (J.-L. Balligand).

\section{References}

1. Gauthier, C., G. Tavernier, F. Charpentier, D. Langin, and H. Le Marec. 1996. Functional $\beta_{3}$-adrenoceptor in the human heart. J. Clin. Invest. 98:556-562.

2. Brodde, O.E. 1987. Cardiac beta-adrenergic receptors. ISI Atlas Sci. Pharmacol. 1:107-112.

3. Ishikawa, Y., and C.J. Homcy. 1997. The adenylyl cyclases as integrators of transmembrane signal transduction. Circ. Res. 80:297-304.

4. Kelly, R.A., J.L. Balligand, and T.W. Smith. 1996. Nitric oxide and cardiac function. Circ. Res. 79:363-380.
5. Balligand, J.L., and P.J. Cannon. 1997. Nitric oxide synthases and cardiac muscle. Autocrine and paracrine influences. Arterioscler. Thromb. Vasc. Biol. 17:24-35.

6. Balligand, J.L., D. Ungureanu-Longrois, W.W. Simmons, D. Pimental, T. Malinski, M. Kapturczak, Z. Taha, C. Lowenstein, A. Davidoff, R.A. Kelly, T.W. Smith, and T. Michel. 1994. Cytokine-inducible nitric oxide synthase (iNOS) expression in adult rat cardiac myocytes: characterization and regulation of iNOS expression and detection of iNOS activity in single cardiac myocytes in vitro. J. Biol. Chem. 269:27580-27588.

7. Balligand, J.L., L. Kobzik, and R.A. Kelly. 1995. Cellular localization of endothelial constitutive nitric oxide synthase in ventricular myocytes from rat and human heart. Circulation. 92(Suppl. I):I-565. (Abstr.)

8. Brady, A.J., J.B. Warren, P.A. Poole-Wilson, T.J. Williams, and S.E. Harding. 1993. Nitric oxide attenuates cardiac myocyte contraction. Am. J. Physiol. 265:H176-H182.

9. Balligand, J.L., R.A. Kelly, P.A. Marsden, T.W. Smith, and T. Michel. 1993. Control of cardiac muscle cell function by an endogenous nitric oxide signaling system. Proc. Natl. Acad. Sci. USA. 90:347-351.

10. Keaney, J.F., J.M. Hare, J.L. Balligand, R.A. Kelly, J. Loscalzo, T.W. Smith, and W.S. Colucci. 1996. Inhibition of nitric oxide synthase augments myocardial contractile responses to $\beta$-adrenergic stimulation. Am. J. Physiol. 40:H2646-H2652.

11. Hare, J., J.F. Keaney, J.L. Balligand, J. Loscalzo, T.W. Smith, and W.S. Colucci. 1995. Role of nitric oxide in sympathetic-parasympathetic modulation of myocardial contractility in normal dogs. J. Clin. Invest. 95:360-366.

12. Han, X., I. Kubota, O. Feron, D.J. Opel, M.A. Arstall, Y.Y. Zhao, P. Huang, M.C. Fishman, T. Michel, and R.A. Kelly. 1998. Muscarinic cholinergic regulation of cardiac myocyte $\mathrm{ICa}-\mathrm{L}$ is absent in mice with targeted disruption of endothelial nitric oxide synthase. Proc. Natl. Acad. Sci. USA. 95:6510-6515.

13. Gauthier, C., K. Laurent, F. Charpentier, E. Drouin, J.C. Chevallier, and H. Le Marec. 1994. Endomyocardial biopsies: a new approach for studying the electrical and mechanical properties of human ventricular myocardium. $J$. Mol. Cell. Cardiol. 26:1267-1271.

14. Bult, H., H.R. Fret, R.M. Vanden Bossche, and A.G. Herman. 1988. Platelet inhibition by endothelium-derived relaxing factor from the rabbit perfused aorta. Br. J. Pharmacol. 95:1308-1314.

15. Garthwaite, J., S.L. Charles, and R. Chess Williams. 1988. Endotheliumderived relaxing factor release on activation of NMDA receptors suggests role as intercellular messenger in the brain. Nature. 336:385-388.

16. Bond, R., and D.R. Clark. 1988. Agonist and antagonist characterization of a putative adrenoceptor with distinct pharmacological properties from the $\alpha$ - and $\beta$-subtypes. Br. J. Pharmacol. 95:723-734.

17. Arch, J.R.S., and A.J. Kaumann. 1993. $\beta_{3}$ and atypical $\beta$-adrenoceptors. Med. Res. Rev. 13:663-729.

18. Kaumann, A.J. 1989. Is there a third heart $\beta$-adrenoceptor? Trends Pharmacol. Sci. 10:316-320.

19. Kaumann, A.J. 1996. (-)-CGP 12177-induced increase of human atrial contraction through a putative third $\beta$-adrenoceptor. Br. J. Pharmacol. 117:93-98.

20. Malinowska, B., and E. Schlicker. 1996. Mediation of the positive chronotropic effect of CGP 12177 and cyanopindolol in the pithed rat by atypical $\beta$-adrenoceptors, different from $\beta_{3}$-adrenoceptor. Br. J. Pharmacol. 117:943-949.

21. Kaumann, A.J. 1997. Four $\beta$-adrenoceptor subtypes in the mammalian heart. Trends Pharmacol. Sci. 18:70-76.

22. Kaumann, A.J., and P. Molenaar. 1997. Modulation of human cardiac function through 4 beta-adrenoceptor populations. Naunyn. Schmied. Arch. Pharmacol. 355:667-681.

23. Han, X., L. Kobzik, J.L. Balligand, R.A. Kelly, and T.W. Smith. 1996. Nitric oxide synthase (NOS3)-mediated cholinergic modulation of $\mathrm{Ca}^{2+}$ current in adult rabbit atrioventricular nodal cells. Circ. Res. 78:998-1008.

24. Hare, J.M., E. Loh, M.A. Creager, and W.S. Colucci. 1995. Nitric oxide inhibits the positive inotropic response to $\beta$-adrenergic stimulation in humans with left ventricular dysfunction. Circulation. 92:2198-2203.

25. Lowes, B.D., W. Minobe, W.T. Abraham, M.N. Rizeq, T.J. Bohlmeyer, R.A. Quaife, R.L. Roden, D.L. Dutcher, A.D. Robertson, N.F. Voelkel, et al. 1997. Changes in gene expression in the intact human heart. Downregulation of $\alpha$-myosin heavy chain in hypertrophied, failing ventricular myocardium. J. Clin. Invest. 100:2315-2324.

26. Méry, P.F., S.M. Lohmann, U. Walter, and R. Fischmeister. 1991. Ca ${ }^{2+}$ current is regulated by cGMP-dependent protein kinase in mammalian cardiac myocytes. Proc. Natl. Acad. Sci. USA. 88:1197-1201.

27. Wahler, G.M., and S.J. Dollinger. 1995. Nitric oxide donor SIN-1 inhibits mammalian cardiac calcium current through cGMP-dependent protein kinase. Am. J. Physiol. 268:C45-C54.

28. Shah, A.M., H.A. Spurgeon, S.J. Sollott, A. Talo, and E.G. Lakatta. 1994. 8-bromo-cGMP reduces the myofilament response to $\mathrm{Ca}^{2+}$ in intact cardiac myocytes. Circ. Res. 74:970-978.

29. Beavo, J.A. 1995. Cyclic nucleotide phosphodiesterases: functional implications of multiple isoforms. Physiol. Rev. 75:725-748.

30. Méry, P.F., C. Pavoine, L. Belhassen, F. Pecker, and R. Fischmeister. 1993. Nitric oxide regulates cardiac $\mathrm{Ca}^{2+}$ current: involvement of cGMP-inhibited and cGMP-stimulated phosphodiesterases through guanylyl cyclase activation. J. Biol. Chem. 268:26286-26295. 
31. Torres, J., V. Darley-Usmar, and M.T. Wilson. 1995. Inhibition of cytochrome $c$ oxidase turnover by nitric oxide: mechanism and implications for control of respiration. Biochem. J. 212:169-173.

32. Gross, W.L., M.I. Bak, J.S. Ingwall, R.A. Kelly, J.L. Balligand, and T.W. Smith. 1996. Nitric oxide regulates rat heart contractile reserve by reversible post-translational modification of creatine kinase. Proc. Natl. Acad. Sci. USA. 93:5604-5609.

33. Campbell, D.L., J.S. Stamler, and H.C. Strauss. 1996. Redox modulation of the L-type calcium channels in ferret ventricular myocytes. Dual mechanism regulation by nitric oxide and $S$-nitrosothiols. J. Gen. Physiol. 108:277-293.

34. Balligand, J.L., L. Kobzik, X. Han, D.M. Kaye, L. Belhassen, D.S.
O'Hara, R.A. Kelly, T.W. Smith, and T. Michel. 1995. Nitric oxide-dependent parasympathetic signaling is due to activation of constitutive endothelial (type III) nitric oxide synthase in cardiac myocytes. J. Biol. Chem. 270:14582-14586.

35. Valenzuela, D., X. Han, U. Mende, C. Fankhauser, H. Mashimo, P. Huang, J. Pfeffer, E.J. Neer, and M.C. Fishman. 1997. G alpha(0) is necessary for muscarinic regulation of $\mathrm{Ca}^{2+}$ channels in mouse heart. Proc. Natl. Acad. Sci. USA. 94:1727-1732.

36. Liggett, S.B., N.J. Freedman, D.A. Schwinn, and R.J. Lefkowitz. 1993. Structural basis for receptor subtype-specific regulation revealed by a chimeric $\beta_{3}-/ \beta_{2}$-adrenergic receptor. Proc. Natl. Acad. Sci. USA. 90:3665-3669. 